\section{Developmental \\ Neuroscience}

Adkins-Regan, E. 342

Alter, M.D. 351

Bales, K.L. 332

Bammer, R. 293

Boone, E.M. 332

Boyce, W.T. 300

Buckmaster, C.L. 293

Carskadon, M.A. 276

Carter, C.S. 332

Champagne, F.A. 318

Curley, J.P. 318

Degnan, K.A. 309

Eliez, S. 293

Epps, A. 293

Fox, N.A. 309

Glover, V. 285
Gunnar, M.R. 251

Hagenauer, M.H. 276

Helfinstein, S.M. 309

Hen, R. 351

Izraelit, A. 318

Jordan, E.R. 318

Kammel, S. 318

Katz, M. 293

Kow, L.-M. 255

Lee, T.M. 276

Liu, C. 293

Loparo, K.A. 259

Lyons, D.M. 293

Martin, E.M. 255

Moseley, M.E. 293

O’Connor, T.G. 285
O’Donnell, K. 285

Obradović, J. 300

Ottet, M.-C. 293

Parker, K.J. 293

Perryman, J.I. 276

Pfaff, D.W. 251, 255

Pournajafi-Nazarloo, H. 332

Reeb-Sutherland, B.C. 309

Schaer, M. 293

Schatzberg, A.F. 293

Scher, M.S. 259

Swaney, W.T. 318

Vannucci, S.J. 255

White, L.K. 309

Zhou, J. 255

\title{
Subject Index Vol. 31, No. 4, 2009
}

Adaptation 351

Amygdala 309

Anoxia 255

Attention bias to threat 309

Chromatin 351

Chronotype 276

Cognitive control 293

Computational phenotypes 259

Copulation 342

Cortisol 285, 293

Curiosity 293

Development 351

Developmental neural plasticity 259

- origins theory 259

Early experience 332

EEG sleep 259

Emotion regulation 293, 309

Endophenotypes 259

Entrainment 276
Epigenetics 351

Fear 293

Fetal programming 285

- /neonatal brain disorders 259

Gene expression, regulation 351

Gene-environment interactions 300

Genomic tone 351

Global 351

HDACs 351

11-ßHSD2 285

Hypoxia 255

Japanese quail 342

Maternal care 318

Negative emotionality 300

Neonate 255, 259

Neurodevelopment 285

Neuroprotection 259

Oxytocin 318, 332

Pairing 342
Patch clamp 255

Physiological reactivity 300

Pitocin 332

Placenta 285

Plasticity 351

Prairie voles 332

Prefrontal cortex 309

Prenatal stress 285

Puberty 276

Reticular formation 255

Sex differences 332

Sexual differentiation 342

- partner preference 342

Sleep deprivation 276

Social behavior 318,342

Vasopressin 318, 332

Weaning 318

Zebra finch 342

\section{KARGER}

๑ 2009 S. Karger AG, Basel

Fax +41613061234 